\title{
Prevalence and characteristics of meticillin-resistant Staphylococcus aureus in humans in contact with farm animals, in livestock, and in food of animal origin, Switzerland, 2009
}

H Huber (ils@fsafety.uzhch) $)^{1,2}$, S Koller ${ }^{1,2}$, N Giezendanner ${ }^{1}$, R Stephan $^{1}$, C Zweifel $^{1}$

1. Institute for Food Safety and Hygiene, Vetsuisse Faculty University of Zurich, Zurich, Switzerland

2. These authors contributed equally to this work

Citation style for this article:

Citation style for this article: Huber H, Koller S, Giezendanner N, Stephan R, Zweifel C. Prevalence and characteristics of meticillin-resistant Staphylococcus aureus in humans in contact with farm animals, in livestock, and in food of animal origin, Switzerland, 2009. Euro Surveill. 2010;15(16):pii=19542. Available online: http:// www.eurosurveillance.org/ViewArticle.aspx?Articleld $=19542$

This article has been published on 22 April 2010

A total of 2,662 samples, collected from March to September 2009 in Switzerland, were tested for the presence of meticillin-resistant Staphylococcus aureus (MRSA). The collection comprised nasal swabs from 148 pig farmers, 133 veterinarians, 179 slaughterhouse employees, 800 pigs, 300 calves, 400 cattle, 100 pooled neck skin swabs from chicken carcasses, and 460 food samples of animal origin. Moreover, 142 $S$. aureus strains, isolated from bovine mastitis milk, were included in the study. Twenty samples ( $<1 \%$; four veterinarians, 10 pigs, three calves, one young bull, and two mastitis milk samples) tested positive for MRSA. Genotyping of the MRSA strains was performed by multilocus sequence typing, spa- and SCCmectyping, and revealed ST398 $(n=18)$, ST8 $(n=1)$, ST 1 $(n=1)$, spa types to11 $(n=7)$, to34 $(n=11)$, to64 $(n=1)$, t127 $(n=1)$, and SCCmec types IV $(n=4)$ and V $(n=16)$. The 20 MRSA strains were subjected to antibiotic susceptibility testing and pulsed-field gel electrophoresis using the restriction enzyme Eagl. Supplementary PCR reactions were performed to investigate the presence of Panton-Valentine leukocidin and staphylococcal enterotoxins $A$ to $D$.

\section{Introduction}

Meticillin-resistant Staphylococcus aureus (MRSA) has become a pathogen of increasing importance in hospitals, the community, and in recent years also in livestock. MRSA associated with livestock (LA-MRSA) have been reported worldwide in many species, but mainly in pigs, with sequence type (ST) 398 found most frequently [1-3]. With regard to humans in contact with farm animals, Voss et al. described in 2005 that Dutch pig farmers were at a 760 -fold risk of being colonised with MRSA compared to the general Dutch population [4]. In an international study, Wulf et al. found MRSA in $12.5 \%$ of veterinarians originating from all over the world [5]. These studies strongly suggest that people working with livestock are at a potential risk of becoming MRSA carriers and hence are at an increased risk of infections caused by MRSA. To date, there is no comprehensive data on the situation of LA-MRSA in Switzerland. The aim of this study was to evaluate the occurrence of MRSA in people in contact with livestock, in farm animals, and in food of animal origin, and to investigate genotypic characteristics as well as phenotypic resistance data of isolated strains.

\section{Methods}

From March to September 2009, we collected and analysed a total of 2,662 samples from humans, livestock, and food of animal origin. In terms of humans with contact to farm animals, we analysed nasal swabs from 148 pig farmers attending meetings on swine breeding, 133 veterinarians participating in a course on castration of piglets, and 179 slaughterhouse employees working in two different abattoirs. Livestock was sampled at slaughter: Nasal swabs from pigs $(n=800)$, calves $(n=300)$, and cattle $(n=400)$ were collected, as well as neck skin samples $(n=100)$ from chicken carcasses, pooled by flock. Sampled animals originated from more than 830 farms distributed throughout Switzerland. In terms of food, 100 samples of bulk tank milk (BTM), 200 samples of raw-milk cheese, and 160 minced pork and beef samples were tested. Furthermore, 142 S. aureus strains from clinical cases of bovine mastitis were integrated in the study.

After a two-step enrichment procedure in MuellerHinton broth supplemented with $6.5 \% \mathrm{NaCl}(24 \mathrm{~h}$ at $37^{\circ} \mathrm{C}$ ) and in phenol red mannitol broth supplemented with $75 \mathrm{mg} / \mathrm{L}$ aztreonam and $5 \mathrm{mg} / \mathrm{L}$ cefoxitin $(24 \mathrm{~h}$ at $37^{\circ} \mathrm{C}$ ), the samples were plated onto Oxoid Brilliance MRSA Agar (Oxoid Ltd., Hampshire, UK) and incubated for $24 \mathrm{~h}$ at $37^{\circ} \mathrm{C}$. In addition, $142 \mathrm{~S}$. aureus strains isolated from bovine mastitis milk were directly streaked onto Oxoid Brilliance MRSA Agar. Presumptive positive colonies were confirmed as $S$. aureus by species-specific 235 rDNA PCR [6] and as MRSA by PCR detection of mecA gene [7], before further characterisation 
by multilocus sequence typing (MLST) [8], spa typing [9], and determination of staphylococcal cassette chromosome mec (SCCmec) type [10] was performed. Moreover, strains were tested by PCR for lukS-PV and lukF-PV [11] encoding Panton-Valentine leukocidin (PVL), and for sea to sed [12] encoding staphylococcal enterotoxins (SE) A to D. To demonstrate phenotypic properties, strains were tested for their antibiotic resistance patterns using the disk diffusion method (BD BBL Sensi-Disc; Becton, Dickinson and Company,
Sparks, MD, US). The following disks were used: ampicillin, cefoxitin, ciprofloxacin, clindamycin, erythromycin, gentamicin, oxacillin, penicillin, rifampicin, sulphamethoxazole/trimethoprim, tetracycline, and vancomycin. Susceptibility testing with cefoxitin is recommended by Witte et al., especially for low-level resistant MRSA [13]. Etest (AB Biodisk, Solna, Sweden) was additionally used for cefoxitin and oxacillin resistance testing. The results of antibiotic susceptibility testing were interpreted according to the guidelines of

\section{FIGURE}

Origin of isolated meticillin-resistant Staphylococcus aureus strains, Switzerland, March-September 2009 (n=20)

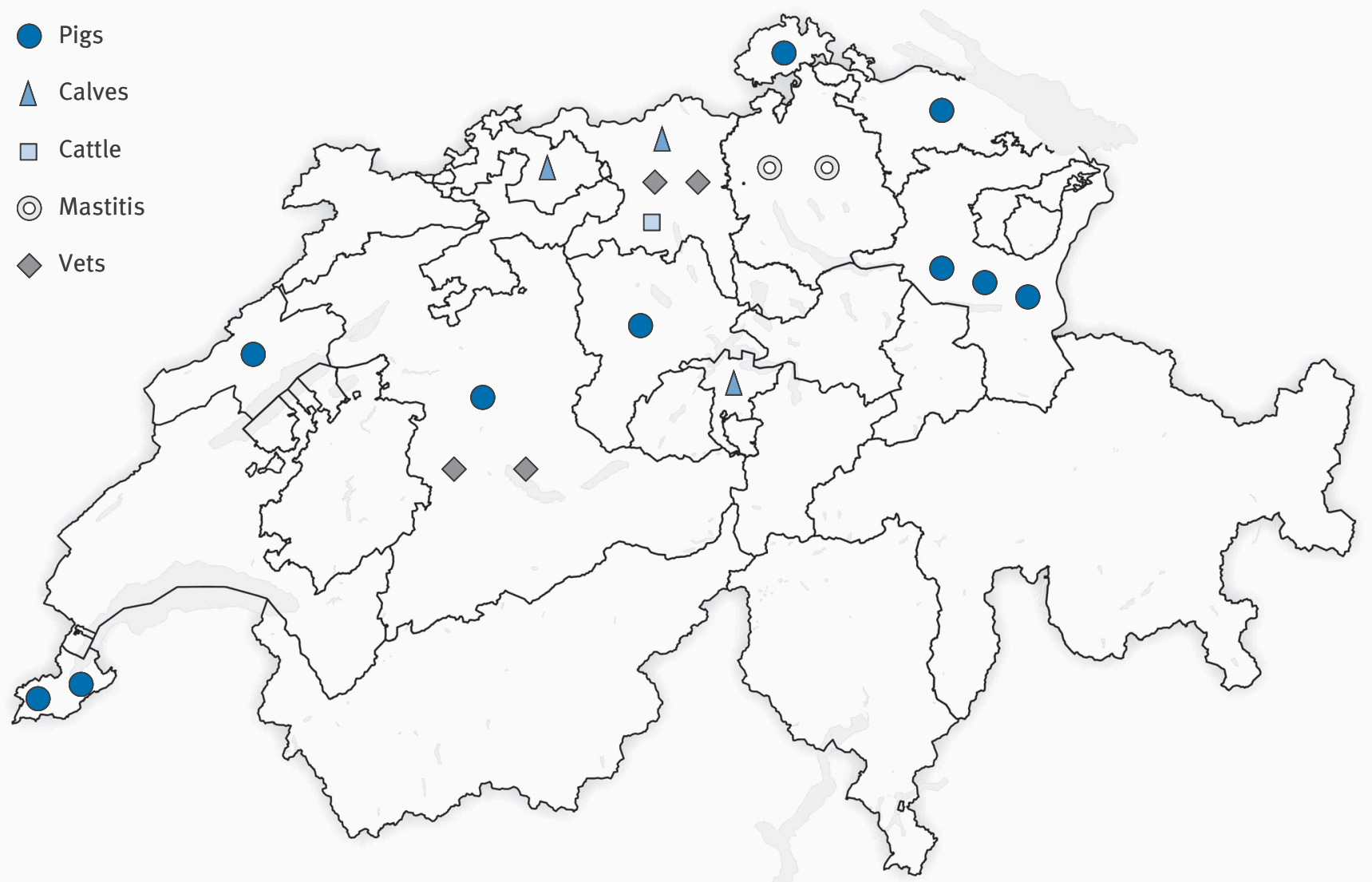

TABLE

Characterisation of meticillin-resistant Staphylococcus aureus strains, Switzerland, March-September 2009 (n=20)

\begin{tabular}{|l|c|c|c|c|c|c|c|}
\hline Origin & Number of isolates & Sequence type (ST) & spa type & SCCmec type & PVL & SE & Resistance \\
\hline Pig NS & 8 & 398 & to34 & V & - & - & Amp, Cef, Cli, Ery, Oxa, Pen, Tet \\
\hline Pig NS & 1 & 398 & to34 & V & - & - & Amp, Cef, Cli, Ery, Gen, Oxa, Pen, SxT, Tet \\
\hline Pig NS & 1 & 398 & to34 & V & - & - & Amp, Cef, Oxa, Pen \\
\hline Calf NS & 3 & 398 & to11 & V & - & - & Amp, Cef, Cli, Ery, Oxa, Pen, Tet \\
\hline Cattle NS & 1 & 1 & t127 & IV & - & - & Amp, Cef, Ery, Oxa, Pen, Tet \\
\hline Vet NS & 1 & 398 & to34 & V & - & - & Amp, Cef, Cip, Cli, Ery, Pen, Tet \\
\hline Vet NS & 1 & 398 & to11 & IV & - & - & Amp, Cef, Oxa, Pen, Tet \\
\hline Vet NS & 1 & 398 & to11 & IV & - & - & Amp, Cef, Gen, Oxa, Pen, Tet, \\
\hline Vet NS & 1 & 8 & to64 & IV & - & A, B & Amp, Cef, Pen, SxT, Tet \\
\hline Mastitis milk & 2 & 398 & to11 & V & - & - & Amp, Cef, Cli, Ery, Oxa, Pen, Tet \\
\hline
\end{tabular}

Amp: ampicillin, Cef: cefoxitin, Cip: ciprofloxacin, Cli: clindamycin, Ery: erythromycin, Gen: gentamicin, NS: nasal swab, Oxa: oxacillin, Pen: penicillin, PVL: Panton-Valentine leucocidin, SE: staphylococcal enterotoxins; SCC: staphylococcal cassette chromosome, SxT: sulphamethoxazole/trimethoprim, Tet: tetracycline Vet: veterinarian. 
the Clinical and Laboratory Standards Institute (CLSI). Furthermore, macrorestriction profiling with pulsedfield gel electrophoresis (PFGE) using the restriction enzyme Eagl was performed [2].

\section{Results}

A total of 20 MRSA strains were detected (Table). They derived from samples from four (3.0\%) of 133 veterinarians, $10(1.3 \%)$ of 800 pigs, three $(1.0 \%)$ of 300 calves, one $(0.3 \%)$ of 400 cattle, and from two (1.4\%) of 142 mastitis milk samples (Figure). In contrast, MRSA were not found in pig farmers, slaughterhouse employees, poultry, and in food samples such as BTM, raw milk cheese, and minced meat.

The four strains isolated from veterinarians belonged to ST8 and ST398 (Table). The strain of ST8 harbored spa type to64, SCCmec type IV, was negative for PVL, and positive for SEA and SEB. This strain of ST8 from a veterinarian was thus the only one harbouring genes encoding staphylococcal enterotoxins. The three strains belonging to ST398 tested negative for PVL and SE. One was spa type to34 and SCCmec type $\mathrm{V}$. The other two strains belonged to spa type to11 and SCCmec type IV. The 10 MRSA strains isolated from pigs originated from eight different farms in seven regions of Switzerland, and all belonged to ST398, spa type to34, SCCmec type $\mathrm{V}$ and tested negative for PVL and SE. These characteristics are the same as those found in one strain from a veterinarian. The results obtained from strains of calves were similar, with the only difference that all three strains were grouped into spa type to11. Two strains from veterinarians were also of ST398 and spa type to11 but belonged to SCCmec type IV. The strain found in a young bull showed different characteristics. It belonged to ST1, spa type t128, SCCmec type IV, and was negative for SE and PVL. The two strains isolated from mastitis milk both belonged to ST398, spa type to11, SCCmec type V and were negative for PVL and SE. According to these typing results, the strains isolated from mastitis are identical to the ones isolated from calves.

Digestion with Eagl as restriction enzyme provided uniform band patterns for nine of 10 strains isolated from pigs. The three strains from calves and the two strains from mastitis milk showed uniform patterns as well and were related to the ones from pigs. The three MRSA strains of type ST398 isolated from veterinarians showed different patterns.

All 20 MRSA strains were susceptible to vancomycin and rifampin. All but two strains were susceptible to gentamicin and sulphamethoxazole/trimethoprim and all but one were susceptible to ciprofloxacin (Table). Of the 16 strains isolated from animals (livestock and mastitis milk), all were resistant to four beta-lactams (ampicillin, cefoxitin, oxacillin, penicillin), 15 were resistant to erythromycin and tetracycline, and 14 to clindamycin. Of the four MRSA strains isolated from veterinarians, two strains were phenotypically susceptible to oxacillin but resistant to cefoxitin, with the disk diffusion as well as the Etest method, and therefore were low-level resistant MRSA.

\section{Discussion}

Our results show that MRSA, and ST398 in particular, are present in Swiss livestock but still occur in low numbers. Compared to the herd level prevalence of $81 \%$ in Dutch pigs [1], the herd level prevalence of MRSA ST398 of $2.9 \%$ in pigs and $1.6 \%$ in calves found in our samples was low. In view of the small proportion of MRSApositive animals found in Swiss livestock, the related risk of food contamination and transmission of MRSA to people in contact with livestock does currently not seem of particular importance in Switzerland. In our study, MRSA prevalence in veterinarians was $3 \%$. This finding is favourable compared to results published by Wulf et al. [5], who found $12.5 \%$ of veterinarians attending an international congress on pig health to be MRSA carriers. Contrary to what was recently reported by De Boer et al. [14], we found no MRSA in meat samples. Our findings in raw-milk cheese and BTM are in good accordance with recently published data from the United States [15]. The fact that we detected no MRSA in poultry, pig farmers, slaughterhouse employees, and food samples is especially noteworthy since these results are different to findings published for other countries $[3,4,13,16]$.

Possible explanations for the low MRSA prevalence in Switzerland may be the restrictive and controlled use of antibiotics in farming, a good health status of pig herds compared to many countries in the European Union, and the fact that the importation rate of live pigs in Switzerland is very low ( $\$ 1 \%)$ [17].

The two non-ST398 strains with ST1 (young bull) and ST8 (veterinarian) found in our study are of sequence types usually considered as community-associated MRSA. Juhász-Kasanyitzky et al. reported MRSA of ST1, spa type t127, SCCmec type IV in humans and bovines [18]. Moreover, such MRSA were also isolated from horses and horse personnel in Austria [19]. The presence of MRSA ST8, spa type to64, SCCmec type IV was recently reported in horses by Weese and van Duijkeren [20].

All LA-MRSA of ST398 found in our study, belonged to two spa types (to34, to11), which represent the most common spa types in European LA-MRSA. Among our samples, spa type to11 was associated with bovine strains, whereas spa type to34 was associated with strains isolated from pigs. The two MRSA strains we isolated from mastitis milk were of ST398 and spa type to11, which is comparable to the recent results of Vanderhaeghen et al. [21]. It seems quite understandable that veterinarians can carry both, spa type to11 and to34, since veterinarians in Switzerland usually visit pig and cattle facilities. Visiting many different farms per day can also be an explanation for the higher 
percentage of MRSA carriers among veterinarians compared to pig farmers.

\section{Conclusion}

MRSA, and especially LA-MRSA ST398, have entered

Swiss farming operations but to date occur in low numbers. This low prevalence suggests that at the moment there is only a limited risk of MRSA transmission from livestock to humans and to food of animal origin. To maintain this situation, further efforts within the field of veterinary public health are of major importance and it is necessary to establish a monitoring system for further trend analysis.

\section{Acknowledgements}

We thank the staff of the slaughterhouses involved in this study for facilitating access to their operation and for assistance with the collection of data, Xaver Sidler for his great effort in making the sampling of veterinarians and pig farmers possible, and Herbert Hächler for his precious assistance in performing antibiotic susceptibility testing.

\section{References}

1. De Neeling AJ, van den Broek MJ, Spalburg EC, van SantenVerheuvel MG, Dam-Deisz WDC, Boshuizen HC, et al. High prevalence of methicillin resistant Staphylococcus aureus in pigs. Vet Microbiol. 2007;122(3-4):366-72.

2. Smith TC, Male MJ, Harper AL, Kroeger JS, Tinkler GP, Moritz $E D$, et al. Methicillin-resistant Staphylococcus aureus strain ST398 is present in Midwestern U.S. swine and swine workers. PLoS One. 2008;4(1):e4258.

3. Persoons D, van Hoorebeke S, Hermans K, Butaye P, de Kruif A, Haesebrouck F, et al. Methicillin-resistant Staphylococcus aureus in poultry. Emerg Infect Dis. 2009;15(3):452-3.

4. Voss A, Loeffen F, Bakker J, Klaassen C, Wulf M. Methicillinresistant Staphylococcus aureus in pig farming. Emerg Infect Dis. 2005;11(12):1965-6.

5. Wulf MW, Sørum M, van Nes A, Skov R, Melcher WJG, Klaassen $\mathrm{CHW}$, et al. Prevalence of methicillin-resistant Staphylococcus aureus among veterinarians: an international study. Clin Microbiol Infect. 2008;14(1):29-34.

6. Straub JA, Hertel C, Hammes WP. A 23 S rDNA-targeted polymerase chain reaction-based system for detection of Staphylococcus aureus in meat starter cultures and dairy products. J Food Prot. 1999;62(10):1150-6.

7. Mehrotra M, Wang G, Johnson WM. Multiplex PCR for detection of genes for Staphylococcus aureus enterotoxins, exfoliative toxins, toxic shock syndrome toxin 1 , and methicillin resistance. J Clin Microbiol. 2000;38(3):1032-5.

8. Enright MC, Day NP, Davies CE, Peacock SJ, Spratt BG. Multilocus sequence typing for characterization of methicillinresistant and methicillin-susceptible clones of Staphylococcus aureus. J Clin Microbiol. 2000;38(3):1008-15.

9. Aires-de-Sousa M, Boye K, de Lencastre H, Deplano A, Enright MC, Etienne J, et al. High interlaboratory reproducibility of DNA sequence-based typing of bacteria in a multicenter study. J Clin Microbiol. 2006;44(2):619-21.

10. Boye K, Bartels MD, Andersen IS, Møller JA, Westh H. A new multiplex PCR for easy screening of methicillin-resistant Staphylococcus aureus SCCmec types I-V. Clin Microbiol Infect. 2007;13(7):725-7.

11. Kocsis E, Lagler H, Pesti N, Stich K, Kristóf K, Nagy K et al. Comparison of Austrian, Hungarian, and Macedonian methicillin-resistant and methicillin-sensitive Staphylococcus aureus strains in relation to prevalence of cytotoxin genes. Microb Pathog. 2009;46(6):328-36.

12. Monday SR, Bohach GA. Use of Multiplex PCR to detect classical and newly described pyrogenic toxin genes in staphylococcal isolates. J Clin Microbiol. 1999;37(10):3411-4.

13. Witte W, Pasemann B, Cuny C. Detection of low-level oxacillin resistance in mecA-positive Staphylococcus aureus. Clin Microbiol Infect. 2007;13(4):408-12.
14. de Boer E, Zwartkruis-Nahuis JT, Wit B, Huijsdens XW, de Neeling AJ, Bosch T, et al. Prevalence of methicillin-resistant Staphylococcus aureus in meat. Int J Food Microbiol. 2009;134(1-2):52-6.

15. Virgin JE, van Slyke TM, Lombard JE, Zadoks RN. Methicillinresistant Staphylococcus aureus detection in US bulk tank milk. J Dairy Sci. 2009;92(10):4988-91.

16. Springer B, Orendi U, Much P, Höger G, Ruppitsch W, Krziwanek $\mathrm{K}$, et al. Methicillin-resistant Staphylococcus aureus: a new zoonotic agent?. Wien Klin Wochenschr. 2009;121(3-4):86-90.

17. Riesen A, Perreten V. Antibiotic resistance and genetic diversity in Staphylococcus aureus from slaughter pigs in Switzerland. Schweiz Arch Tierheilkd. 2009;151(9):425-31.

18. Juhász-Kasanyitzky E, Jánosi S, Somogyi P, Dán Á, van der Graaf-van Bloois L, van Duijkeren E, et al. MRSA transmission between cows and humans. Emerg Infect Dis. 2007;13(4):630-2.

19. Cuny C, Stommenger B, Witte W, Stanek C. Clusters of infections in horses with MRSA ST1, ST254, and ST398 in a veterinary hospital. Microb Drug Resist. 2008;14(4):307-10.

20. Weese JS, van Duijkeren E. Methicillin-resistant Staphylococcus aureus and Staphylococcus pseudintermedius in veterinary medicine. Vet Microbiol. 2010;140(3-4):418-29.

21. Vanderhaeghen W, Cerpentier T, Adriaensen C, Vicca J, Hermans K, Butaye P. Methicillin-resistant Staphylococcus aureus (MRSA) ST398 associated with chlinical and subclinical mastitis in Belgian cows. Vet Microbiol. 2010 (in press). 